\title{
Development of decision-making tools to create a harmonised UK national mineral resource inventory using the United Nations Framework Classification
}

\author{
T. Bide *, T.J. Brown, A.G. Gunn, E. Deady \\ British Geological Survey, Keyworth, Nottingham, NG12 5GG, UK
}

\section{A R T I C L E I N F O}

\section{Keywords:}

Mineral resource

UNFC

Resource management

Resource classification

Critical minerals

\begin{abstract}
A B S T R A C T
The need to better understand how we source and consume the raw materials required for decarbonisation is driving a growing demand for data on mineral resources. A key application of these data is to understand resource potential, by evaluating known 'geological stocks' of raw materials based on estimates of mineral resources and reserves. However, the available resource data are often incomplete, totally lacking or compiled in different ways (i.e. industry reported data, which has significantly different user requirements to that of national level policy makers), making comparisons and aggregation near impossible.

This study demonstrates the use of the United Nations Framework Classification (UNFC) to harmonise resource data for the UK. It highlights the benefits of this approach for improving the understanding of resource issues. Simple decision-making tools have been created, and are used to assist with classifying existing resource data using the three axes of UNFC, degree of confidence, technical feasibility and environmental socio-economic viability. These are designed to be applicable to a wide range of heterogenous datasets managed by national data providers. Their application to the UK, which has no system or national standard for collecting resource data, has served to highlight various issues relating to future mineral supply. These include variable data for deposits that may include multiple commodities such as co- and by-products, lack of data for minerals required for newly developing technologies and the variations in approaches for different commodity types.

The compilation of standardised datasets can benefit national resource management, providing a 'snapshot' of the state of the UK minerals industry. For example, the results of this study facilitates inter-regional and international comparison and aggregations. In addition the consideration of the unique combination of geological, social and environmental factors by UNFC well as highlights where interventions may be needed if new projects to contribute to the green transition are to be developed. The use of the UNFC to classify mineral resource data, in a consistent way, by using the decision tools presented here, supports the creation and adoption of evidencebased raw material strategies. However, it is important to understand the limitations related to data gaps, consistency of approach and harmonisation of datasets from diverse sources.
\end{abstract}

\section{Introduction}

Although it is clear that all European countries are highly dependent on mineral raw materials, essential for European industries, jobs and growth (European Commission, 2008, 2020), it can be difficult to gather statistical data for European, or even national, mineral resources. The inability to easily produce reliable statistics about reserves or resources of raw materials directly leads to uncertainty surrounding supply security and is a major concern for policymakers, such as national governments or the European Commission (Department For Environment,

\section{2; European Commission, 2008).}

Evaluating known 'geological stocks' of raw materials (i.e. the amount of raw materials contained within known geological formations and mineralised terranes) is key to understanding the overall resource potential of Europe. Without adequate understanding of these geological stocks, it is difficult to manage and plan to meet current and future demand using domestic resources where possible. Such plans are crucial if high level objectives are to be achieved, such as decarbonising energy supplies, achieving a circular economy and reducing the environmental footprint of mineral extraction.

\footnotetext{
* Corresponding author.

E-mail address: tode@bgs.ac.uk (T. Bide).
} 
This paper describes the issues surrounding the provision of reliable and comparable baseline data for resource management and reviews the different ways in which mineral resources are defined. This study only concerns non-energy mineral resources, although it should be noted that resource classifications which have been developed for petroleum resources are also relevant and have been developed alongside those of solid minerals. It presents the United Nations Framework Classification for Resources (UNFC) as a potential solution for the creation of a standardised dataset of this type, using the mineral resource inventory of the UK as an example of how this can be achieved on a national level. This standardisation has been achieved by use of a series of decisionmaking tools this study has developed, designed to aid in applying a level of constancy in classifying national level data according to UNFC.

\section{Definition and classification of mineral resources}

A mineral resource is defined as a natural concentration of material in such form and quantity that economic extraction of a commodity is potentially feasible (CRIRSCO, 2016; McKelvey and Kleepe, 1976; UNECE, 2019) Reserves are that part of an identified resource that could be economically extracted at the time of the assessment, taking into account the 'modifying factors' (these are the external influences that need to be considered, such as legal permissions, mining methods, geometallurgy, processing technology, socio-economic and environmental factors). Comprehensive reviews of the history, standards, definitions and classifications used can be found in many comprehensive sources. For instance, Crowson (2011) which explores the concepts required for assessing resources and reserves, Henley and Allington (2013), which discusses the differences between the CRISCO and UNFC systems, McKelvey and Kleepe (1976), which outlines the initial concepts of reserve and resource classification systems, which almost all subsequent systems have built on and Stephenson and Weatherstone (2006) which gives a comprehensive overview of the various reporting mechanisms and their various strengths and weaknesses. Mineral resources and reserves are of fundamental importance to most extractive industries and to the bodies responsible for resource management, such as national governments, who may rely on tax revenue from the extractive sector and feedstocks for critical industries. Accurate information presented in a clear and easily understandable format is also essential for the global mining industry, enabling them to convey a project's status to investors.

Separate jurisdictions have developed different ways of measuring and reporting mineral resources and reserves designed to fit the individual requirements of specific regions, nations or industries. Various reporting systems set out minimum standards, recommendations and guidelines for the public reporting of exploration results, mineral resources and reserves. Many of the individual standards and codes used by industry, as well as some national standards, have been incorporated into an internationally recognised template, referred to as the Committee for Mineral Reserves International Reporting Standards (CRIRSCO). This is the industry standard and has been set up to promote best practice in the international public reporting of mineral exploration results, mineral resources and mineral reserves. CRIRSCO members include Australasia (JORC Code), Brazil (CBRR), Canada (CIM Code), Chile (Comisión Minera), Columbia (CCRR), Kazakhstan (KAZRC), India (NACRI), Indonesia (KOMBERS), Mongolia (MPiGM), South Africa (SAMREC Code), Turkey (UMREK), United States (SME Guide), Russia (NAEN Code) and Europe (PERC Reporting Standard).

The CRIRSCO family of codes has been designed specifically for the reporting of results to stock exchanges and regulators, where it is essential that investors have accurate information to ensure confidence in the industry. For example, in Australia companies listed on the Australian Securities Exchange are required to use the code of the Australasian Joint Ore Reserves Committee (JORC). Similarly, companies that report their results on stock exchanges in Canada are required to follow the rules and guidelines of National Instrument (NI)
43-101. As a result of this any 'reserves' or 'resources' stated are economic entities that have a realistic chance of being extracted in the near future, determined by numerous variables including discovery and extraction rates, technologies for extraction, processing and use, and various political, legal, economic and social factors that influence their accessibility. Reserves can be regarded as working inventories and the size of a mineral reserve is critically dependent on the commodity price prevailing at a particular time. As a result of their dynamic nature and the inherent uncertainties in global and national totals, published reserve estimates should not be regarded as reliable indicators of the future availability of mineral commodities. This concept is explored in Crowson (2011), which outlines the complexities, and common misunderstandings involved in the use of reserve and resource data, Jowitt et al. (2020), which dismisses the concept of 'peak mineral' and how geological availability is unlikely to cause a limiting effect on supply, this is further explained in Lusty and Gunn (2015) and Meinert et al. (2016) which discuss the unsuitability of reserve data for assessing future supply.

Data reported to the CRIRSCO template can be regarded as having high confidence and quality, because the individual codes (PERC, JORC etc.) are clearly defined standards, backed by professional bodies and by the requirement for compilation by a 'competent person' whose qualifications are clearly defined (CRIRSCO, 2016; Henley and Allington, 2013). This level of confidence is demonstrated by the wide acceptance of this data for the stringent requirements required by national stock exchanges. However, CRIRSCO is not designed for the purpose of national- or continent-scale strategic planning or policy making. It cannot accommodate all that needs to be considered for national level geological stock management and reporting. There is no provision to record anything that is not currently economic. As a result, the figures are a 'snapshot' of what is economic to extract now or will be in the near future (several years). The CRIRSCO family of codes do not consider known, but poorly defined, deposits or anything that is not currently worked due to environmental or economic constraints. Consequently, they are not a true representation of the total mineral inventory of a country or region. Much of the research undertaken by governments and national geological surveys will most likely not adhere to the CRIRSCO template because it mostly relates to early-stage exploration or non-commercial research. However, such data are crucial for long term planning and resource management by nation states.

National standards and classifications have also been developed as part of natural resource management practices as opposed to being investor focused, for example the Russian classification (Russian Federal Government Agency State Commission on Mineral Reserve, 2008). Various professional bodies have attempted to harmonise definitions and reporting standards but substantial differences remain (Crowson, 2011; Henley and Allington, 2013), the most fundamental being the range of what is considered a resource, and the different confidence limits applied.

The United Nations Framework Classification (UNFC) for Fossil Energy and Mineral Resources (UNECE, 2019) is an international classification system for resource data, including mineral resources. This is focused on the development of a consistent set of definitions across commodity types and international bodies and is not developed with the purpose of investor reporting. It has been developed under a mandate from the UN Economic and Social Council and serviced by the Expert Group on Resource Classification (EGRC) of the United Nations Economic Commission for Europe (UNECE). The UNFC is a classification system that is flexible enough to be used at both national and international levels and can be used for international communication and comparison of resources in trans-national assessments. It has been adopted (or is in the processes of being adopted) as a national resource management system in numerous jurisdictions, i.e. at a continental level in Africa and on a national level in countries such as Mexico, India and Ukraine (Blengini et al., 2020; Carpenter, 2020; Grohol, 2020; Indian Bureau of Mines, 2003; UNECE, 2018b). 
It should be emphasised that UNFC is a classification and not a full reporting standard. It provides no guidance on data quality or validation, or on methods or formats of reporting. The UNFC system has been designed to create mineral inventories in a harmonised way that can be easily combined across regions and national borders and that can be used to underpin mineral policies and planning. Unlike the CRIRISCO template, the UNFC can accommodate 'uneconomic' and 'undiscovered' resources, including early stage exploration or deposits that are not economic to extract under current market conditions, thus giving a fuller picture of geological stocks of minerals.

There have been many projects in recent years to enable it to be compared to, or 'bridged' with, other international standards and codes. These have considered CRIRSCO-compliant figures (UNECE, 2015) as well as national systems e.g. China (UNECE, 2018a), Hungary (Horváth, 2018), Russia (FGU et al., 2010), Nordic countries (Kaj et al., 2018), the Czech Republic (Ministry of the Environment of the Czech Republic, 2016) and Poland (Polish Geological Institute, 2017). National resource inventories have also been produced for other natural resources that the UNFC covers, such as geothermal energy (Falcone and Conti, 2019). European-funded projects such as ORAMA (Wagner et al., 2019) and Mintell4EU (Pedersen et al., 2019) are also gathering and creating case studies demonstrating how UNFC can be used in Europe to overcome harmonisation issues.

\section{Publicly available data for resource management}

Much work has been undertaken in recent years to better understand the nature of geological stocks of mineral resources on national and European levels. This was first attempted by the ProMine project (2009-2013), which began to develop a method for compiling continental-scale spatial data for mineral deposits in Europe (Cassard et al., 2015). This was followed by the Minventory project (2011-2014), which outlined a route to harmonise and compile some of the substantial datasets that had been complied by other European projects (Parker et al., 2015). The Minerals4EU Project (2013-2015) continued the spatial data work started by ProMine and was also the first to attempt to gather and compare resource statistics on a national level for over 40 European countries (Brown and Petavratzi, 2015). This was the first time that statistics on mineral resources and reserves were collected at the European level and have been made publicly available through the European Minerals Yearbook (Minerals4EU project, 2015). The work of the early inventory-based projects was further developed by the ORAMA project (2017-2019), which produced a detailed roadmap as to how minerals data can be improved and harmonised across Europe (Wagner et al., 2019).

The Minerals4EU project showed that in Europe data are compiled according to no less than 19 different systems used in the 1st edition of the European Minerals Yearbook (Brown and Petavratzi, 2015) and more systems are known to exist that were not reported. In many cases, these codes are not comparable and cannot be summed together. Some countries use their own unique national reporting systems, while others use a multiplicity of different codes and standards. Furthermore, the age of the datasets varied considerably. Some figures are undated 'historical' estimates, while others are modern estimates based on current international reporting systems. As a result, any national or pan-European totals derived from summing reserve or resource estimates obtained by these projects would be incomplete and fundamentally flawed. They would provide no indication of the current availability of a commodity within Europe, nor of the potential for future development or discovery. Such incomplete data can provide little contribution to understanding and managing stocks of minerals and may even lead to incorrect assumptions being made about resource availability, leading to poor policy development and resource management strategies. Detailed analyses (Bide et al., 2019b; Brown and Petavratzi, 2015) showed that comparison of national level datasets was at best difficult and at worst impossible for these reasons.

\section{Data harmonisation solution}

It is recognised that it is unlikely that individual countries would be willing or able to change their current systems of working because many have a legal foundation and have been developed for specific purposes. However, in order for them to be consistent and comparable across borders they need to be converted to a single harmonised system. This approach has been described in previous research, originally in a 'roadmap to achieve European harmonisation by Parker et al. (2015) and subsequently via the results of data collection from the Minerals4EU project (Petavratzi and Brown, 2017) and the ORAMA project which provided recommendations on how to achieve data consistency (Bide et al., 2019a; Wagner et al., 2019).

The UNFC system is designed to harmonise diverse resource data from different sources. However, it can appear complex to non-experts and is still not widely adopted. To better understand how it can be used for the wide variety of resource geodata that national geological surveys typically hold, this study attempts to classify resource data held by the British Geological Survey (BGS) using the UNFC.

Any classification exercise cannot be undertaken without a detailed understanding of mineral stocks within the subject country. This study was carried out as part of the ORAMA project (2017-2019), which looked at European resources data holistically to recommended improvements to achieve interoperability on a European level.

The UK has no system for collecting mineral resource data and no specific standards or definitions are present in national legislation. Accordingly, the UK provides a good, if complex, example of how the UNFC system can be used to produce a national resource inventory that can be compared with those of other countries that also use UNFC. This study uses baseline data compiled by a resource inventory exercise for the UK (Bide et al., 2020) for this classification exercise.

\section{Methodology}

\subsection{The use of UNFC}

The UNFC system is a numerical coding scheme, which is used to classify quantities on the basis of three fundamental criteria: environmental-socio-economic viability (E); technical feasibility (F); and degree of confidence (mostly related to geological knowledge) (G). Combinations of these criteria can be displayed and visualised in three dimensions or reduced to two dimensional presentations (Fig. 1). Each of these axes are given a value, from 1 to 3 or 4,1 representing the highest level of confidence, 3 or 4 representing the lowest. Detailed guidance documents on the use of UNFC are available from the UNECE (Kaj et al., 2018; UNECE, 2019).

Due to the unique nature of many resource projects, certain categories on all 3 axes have been subdivided under the UNFC scheme to provide further information as to a project's status. However, for this study, which is a preliminary attempt at utilising UNFC for a national inventory, these subdivisions have not been used. Ideally subdivisions should be incorporated for more detailed classifications in future iterations.

In order to minimise subjectivity in classifying resources, a systematic and objective decision-based process was adopted. It is also important to note that categories highlighted in Fig. 1b may be the most used and represent the vast majority of cases but all combinations are possible and valid. Another feature of UNFC is the potential for aggregated axis numbers under specific conditions, i.e. $\mathrm{G} 1+\mathrm{G} 2$ is applicable if both 'measured' and 'indicated' (as defined by the CRIRSCO template) are reported as an aggregated figure.

The first step in the classification process involved the development of decision-support tools to assist with decision-making for each axis of UNFC (Fig. 2) (Brown et al., 2019). Due to the unique features of individual mineral deposits and projects, the decision-support tools are not necessarily prescriptive but form a framework around which 
a)

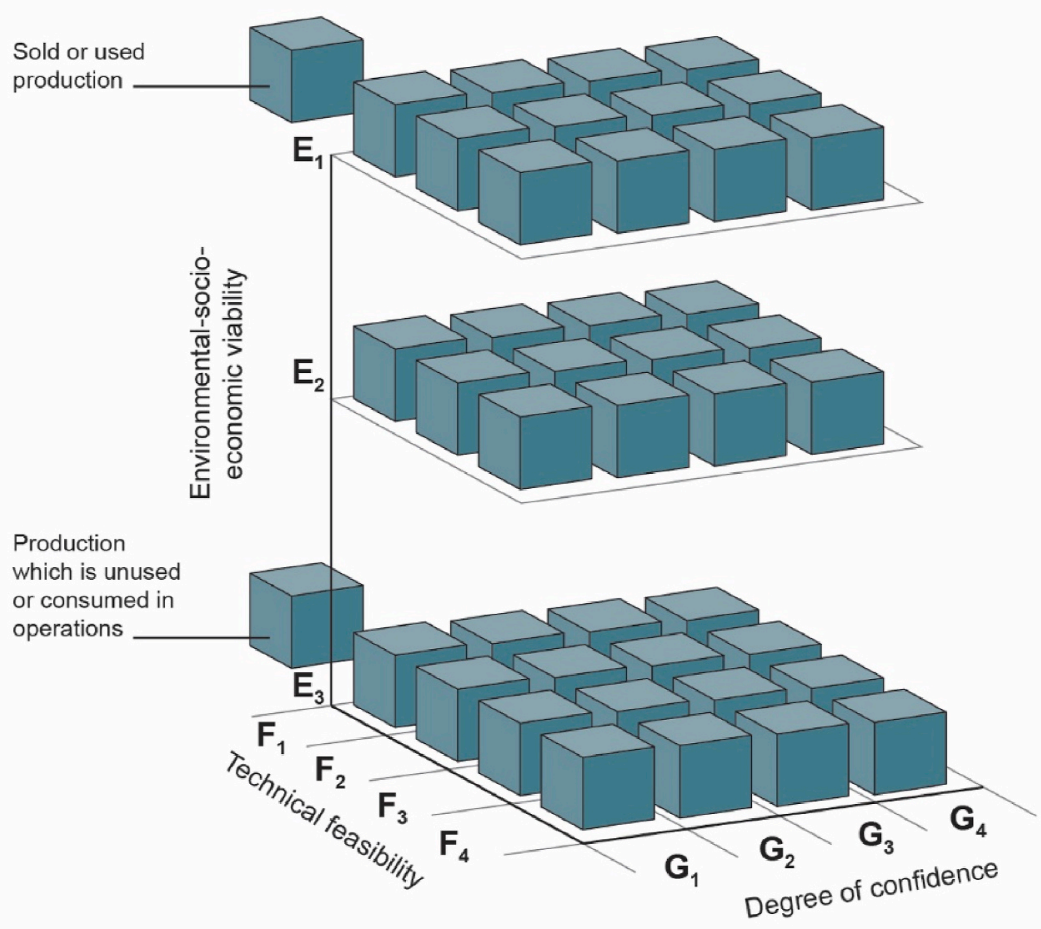

b)

\begin{tabular}{|c|c|c|c|c|}
\hline & \multirow{2}{*}{ Class } & \multicolumn{3}{|c|}{ Minimum Categories } \\
\hline & & $\mathrm{E}$ & $\mathrm{F}$ & $\mathrm{G}$ \\
\hline $\begin{array}{l}\text { The project's environmental-socio-economic viability and } \\
\text { technical feasibility has been confirmed }\end{array}$ & Viable Projects & 1 & 1 & $1,2,3$ \\
\hline \multirow{2}{*}{$\begin{array}{l}\text { The project's environmental-socio-economic viability } \\
\text { and/or technical feasibility has yet to be confirmed }\end{array}$} & $\begin{array}{l}\text { Potentially } \\
\text { Viable Projects }\end{array}$ & 2 & 2 & $1,2,3$ \\
\hline & $\begin{array}{l}\text { Non-Viable } \\
\text { Projects }\end{array}$ & 3 & 2 & $1,2,3$ \\
\hline \multicolumn{2}{|l|}{ Remaining products not developed from identified projects } & 3 & 4 & $1,2,3$ \\
\hline $\begin{array}{l}\text { There is insufficient information on the source to assess } \\
\text { the project's environmental-socioeconomic viability and } \\
\text { technical feasibility }\end{array}$ & $\begin{array}{l}\text { Prospective } \\
\text { Projects }\end{array}$ & 3 & 3 & 4 \\
\hline \multicolumn{2}{|l|}{ Remaining products not developed from prospective projects } & 3 & 4 & 4 \\
\hline
\end{tabular}

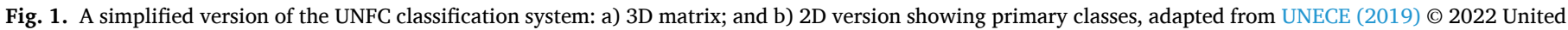
Nations. Reprinted with the permission of the United Nations.

classification decisions can be made. The decision trees were developed as part of an iterative process with a range of stakeholders who supplied feedback as to their usefulness. The tools allow for identification of the main factors that delineate UNFC classes with simple yes/no answers to a range of common scenarios. These tools are not intended to provide exhaustive coverage of all possible scenarios (the range of different minerals projects, and data are near impossible to capture in this simplistic way). They are intended to provide a guide to ensure consistency in UNFC classification by those with expertise in resources rather than an aid to non-experts. They also may be less suited for use with resourced data adhering to Russian style reporting codes, which set clear bounds on probabilities for different categories, and as such are often is less subjective. 
a)

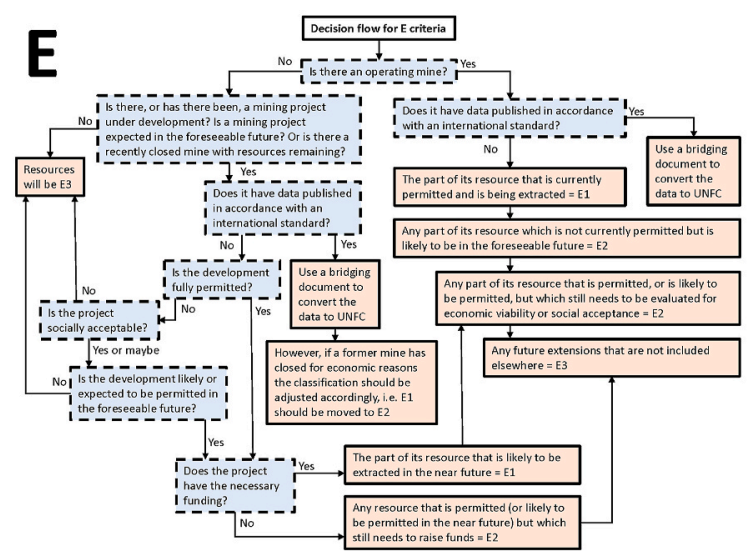

b)
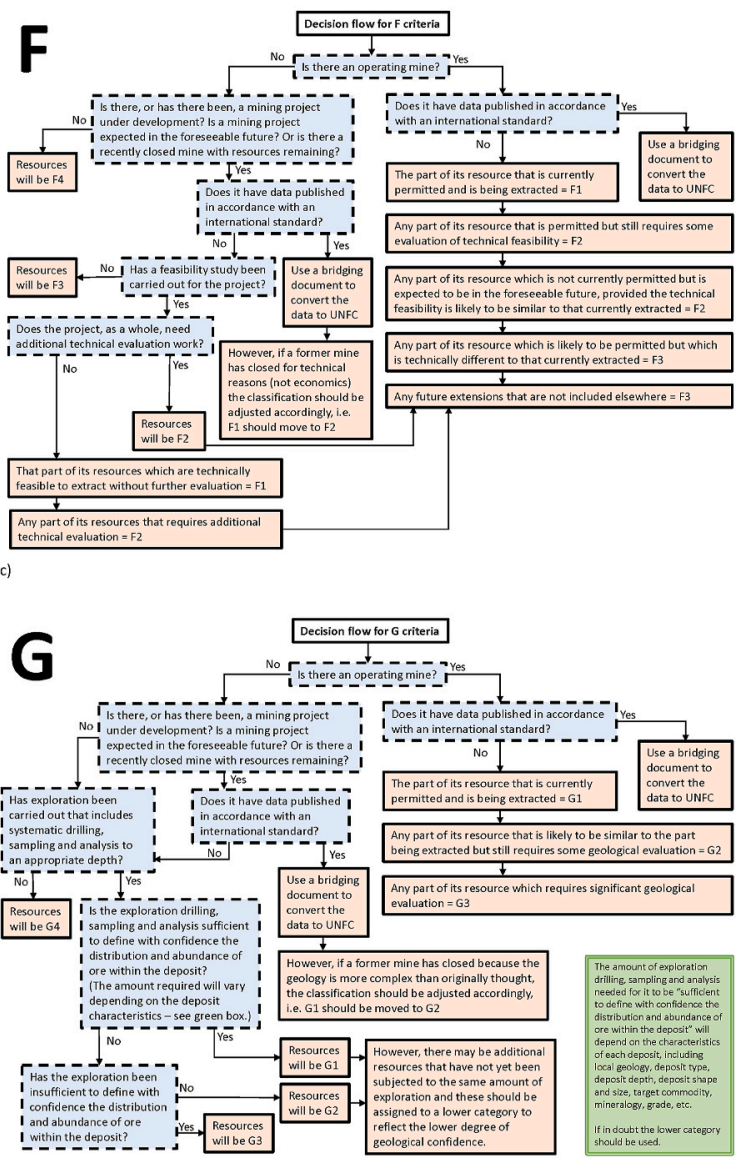

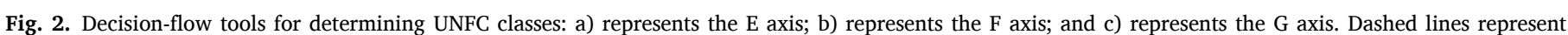

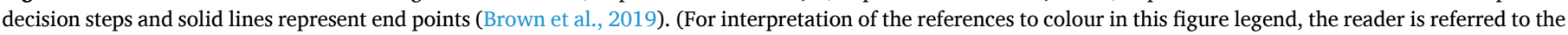
Web version of this article.)

\subsection{Application of UNFC to the UK resource inventory}

The UK resource inventory comprises a wide variety of different data types, a situation typical of national data sets held by organisations such as geological surveys. Each data source required an individual approach and had its own unique issues that required consideration. The data can be split into three categories:

- data supplied and/or published by the extractives industry

- historical data held in research reports and academic studies

- data created using geospatial analysis

\subsubsection{Data supplied by the extractives industry}

Data supplied by the minerals industry is generally the simplest to classify using UNFC. Industry data will frequently be classified to established standards, generally the CRIRSCO template, from where bridging documents to UNFC are well established and can be used (UNECE, 2015). For the majority of the UK deposits with CRIRSCO-compliant data, these data are publicly available direct from individual company reports, on company webpages or in trade association commodity reviews.

Bridging from CRIRSCO to UNFC is not always a one-to-one association but a one-to-many association, i.e. a single category in CRIRSCO may bridge to two or more categories in UNFC. Therefore, more information may be required at the mineral deposit level to ensure it is correctly classified. Consequently, an additional decision-making tool to show how CRIRSCO-compliant data can be classified according to UNFC has been developed (Fig. 3) (Brown et al., 2019).

Despite this apparent simplicity, it is important to note that there may be additional resources associated with a mineral deposit, which are not captured by the CRIRSCO template, and will be missing for these deposits as they may be considered sub-economic (i.e. they will not be considered a resource by the CRIRSCO template). This is a significant data gap. In some instances, this 'missing' resource can been included in this analysis by the examination of historical estimates, if available, (detailed below) but in other cases data may not be available to quantify this 'sub-economic' portion. Consequently, the figures presented do not represent 'all there are' within the country in most instances, but rather then minimum. The figure for 'all there is' is only possibly by detailed regional mineral exploration and/or regional scale modelling and spatial analysis.

The integration of industry data and historical data rarely causes conflict as the levels of confidence attribute to the two different sources are rarely the same. For example, industry data will almost be higher confidence (categories around 1 or 2 in UNFC) whereas historical data will generally be categories 3 and 4 . The identification and cross referencing of industry and historical data however requires a significant amount of geological knowledge.

For metallic mineral deposits, commodity-specific cut-off grades are often applied. In this study, where multiple cut-off grade values were reported for a particular commodity, the lower value was used. Data for CRIRSCO-compliant resources of metallic commodities in the UK are presented as metal content. These were calculated by multiplying tonnage by grade on a deposit scale before summation to generate a total for the UK. This has the disadvantage of losing the detail that can be 


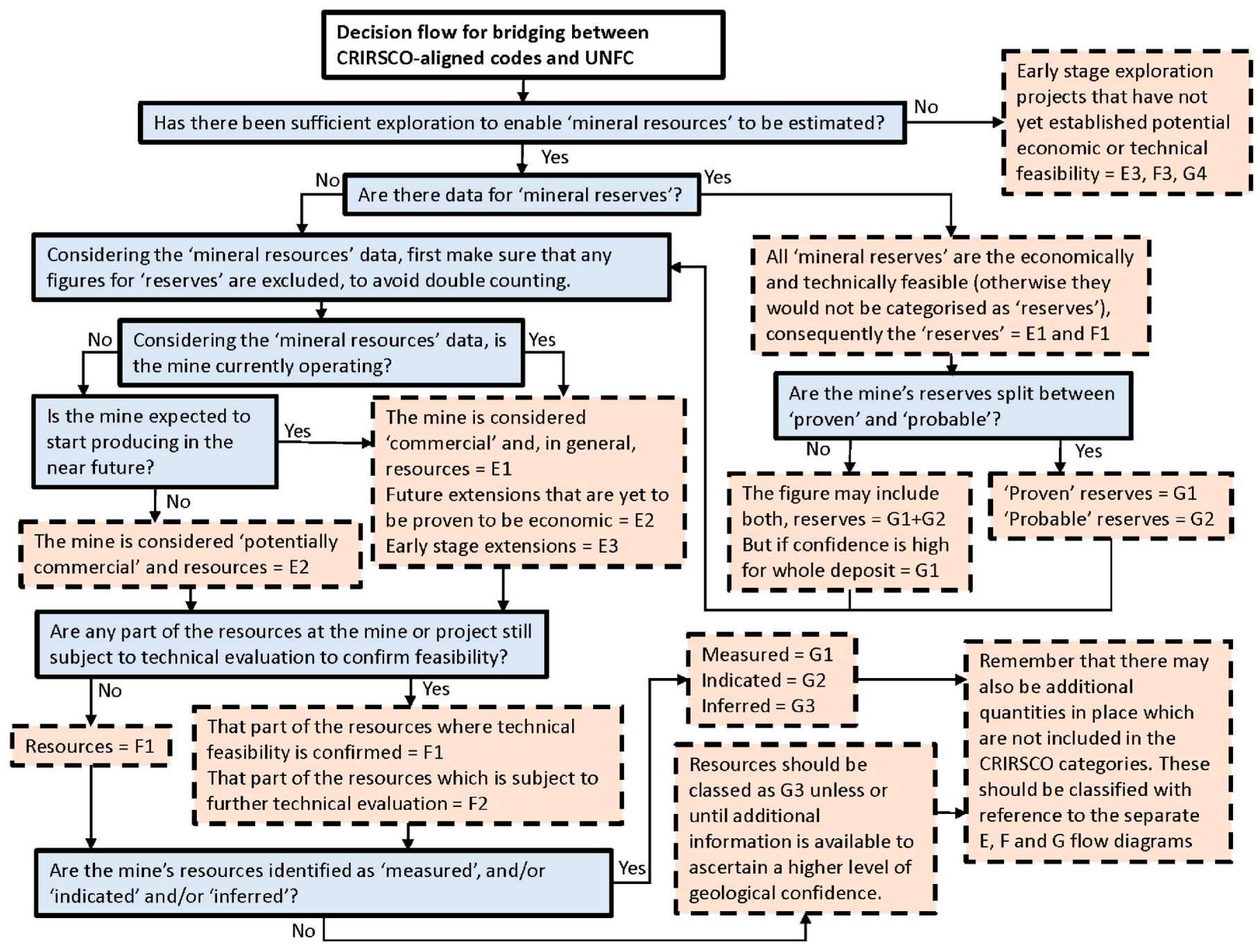

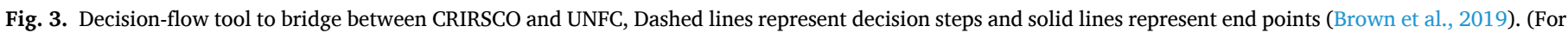
interpretation of the references to colour in this figure legend, the reader is referred to the Web version of this article.)

obtained regarding the size and scale of a deposit from the metal grades but was the only achievable way to aggregate data from different deposits for this study.

\subsubsection{Historical data}

National geological surveys, mining ministries and government departments commonly hold a wealth of information on mineral resources in reports of exploration activity, scientific studies and academic research. These historic data highlight gaps in knowledge not covered by modern CRIRSCO-compliant data. For example, less well characterised, or currently sub-economic deposits and occurrences may represent potential future resources and it is therefore important to capture them in a national inventory.

Determining the appropriate UNFC category is challenging for such historic data because it is first necessary to assess what level of confidence one can have in the data in relation to the complexity of the deposit type. For example, a significant amount of data in the form of boreholes and geochemical analysis is required to have reasonable levels of geological confidence when assessing complex metallic mineralisation, such as epithermal gold deposits, whereas geologically simpler deposits, such as bedded deposits of industrial minerals, may require less data to ascertain the same level of confidence. Therefore, no simple rules can be applied and a detailed knowledge of the mineral deposits, together with an understanding of the scope and capability of historic data, is required to understand the complexities when applying UNFC classes. In these complex examples the decision tools in Fig. 2 provides guidance and help to ensure consistency.

For historical data it is unlikely that the $\mathrm{E}$ or $\mathrm{F}$ axis categories will be higher than 'E3' and 'F3' because any technical, economic or social considerations that were true at the time of reporting are unlikely to still be relevant. The category of ' $F 4$ ' has been occasionally used for historical data for regional studies where individual deposits may not have been specified. Such examples of 'occurrence-based' data (as opposed to deposit specific examples) are discussed further in the geospatial data section.

Much of the historic data for metallic minerals has been classified to UNFC 'E3 F3 G3'. This seems most appropriate if deposit-specific exploration has taken place but development is not expected in these areas in the foreseeable future. In the vast majority of cases, exploration was at too early a stage to adequately assess environmental and socioeconomic viability, there is insufficient data to evaluate the technical feasibility of the deposit and quantities have been estimated with low levels of confidence. However, in some cases the ' $G$ ' category may be 'G2' if adequate drilling/ground investigations were undertaken. Similarly, in some cases ' $\mathrm{G} 4$ ' may be appropriate, if the geological evidence is insufficient for the deposit type in question. Often the geological evidence base for historical data will be incomplete making classification difficult, when in doubt the lowest confidence category has been 
applied.

\subsubsection{Geospatial data}

Due to the lack of a centralised or systematic collection of data for mineral resources in the UK, data for many commodities that are not reported for confidentiality reasons or were subject to historic exploration are not available. This is the case for many construction and industrial minerals. As a result, national and regional level estimates have been made using geospatial data in a Geographic Information Systems (GIS) environment for the purposes of a national inventory. This relies on data inferred from geological mapping, rather than supplied by the industry and the methodology used to undertake this exercise is described fully in Bide et al. (2020).

The geospatial analysis approach estimated resource quantities on a regional or national scale rather than on the scale of individual deposits. The results of such studies are difficult to integrate into the UNFC system as it is primarily designed for examining resource quantities at a deposit level. However, it is still possible to use such data within the UNFC framework where it will almost always be attributed to the ' 334 ' or ' 344 ' classes due to low levels of confidence in all 3 axes. The distinction between 'F3' or 'F4' will be based on whether specific deposits, or active mines or quarries have been identified within the area of resources identified using geospatial analysis.

This highlights one of the significant issues of including such undefined data in the UNFC framework. There are some instances where individual deposits will have been incorporated into larger regional and national figures that include resources over the entire geological outcrop or subcrop (the buried part of a geological formation). Where possible, these individual deposits should be separated out and removed from the geospatial analysis because they could be classified differently. The UNFC is a mutually exclusive scheme and higher confidence classes should not be included in lower ones. However, if no figures for resources for the individual deposits are available, inevitably they will be incorporated into the broader geospatial area and its associated figures.

The lack of deposit-specific data is common in the case of industrial and construction minerals where information regarding the size of deposits is often not publicly available for confidentiality reasons, especially where there is no requirement for public reporting, such as for private companies. Consequently, it is likely that data arising from the geospatial analysis approach relate to a range of categories on the $\mathrm{E}$ and $\mathrm{F}$ axes of the UNFC system. For this UK study, in these instances, the data have been allocated to the lowest class of confidence and detailed explanatory footnotes have been applied. Whilst such use of footnotes is acceptable within the UNFC framework it is not best practice and should be addressed in subsequent iterations where better resolution data for known deposits should be sought if available.

\section{Results of UNFC for the UK}

Table 1 provides the full results of the classification of the UK minerals inventory according to UNFC with the aid of the decision trees (Figs. 2 and 3). Individual cells have been coloured according to the attributed UNFC class to give a clear representation of the UNFC axes in a 2D format. For each commodity, this shows how the data move from high to low confidence from the top left to bottom right of each section. Generally, the quantity of the mineral commodity decreases as confidence increases, highlighting how the volume of resources available for extraction are significantly less than the overall quantity that may be physically present in the ground.

Although this inventory is as comprehensive as possible within the limitations of the available data, it must be recognised that for many commodities the data presented do not represent 'all there is' in the ground. It is likely further resources remain in undiscovered deposits, which are very difficult to quantify without further exploration. These undiscovered resources are discussed on an individual commodity basis in Bide et al. (2019b). The results also included certain classifications as 'not quantified' where these were known to exist, and therefore needed to be recognised, however no data exist to quantify them.

\section{Discussion}

\subsection{Using UNFC as a resource management tool}

Presentation of the UK resource inventory using UNFC classes (Table 1) highlights the various states of availability at the present of various commodities on a national level, the current data that exists and how the resources might be developed. For example, for the majority of the metallic minerals there is a lack of material in the ' 1 ' class, in any axis. This highlights that very few metal mines are in production, or projects that will be ready for development in short timescales. However, the abundance of ' 3 ' and ' 4 ' classes in all axes shows that there is an abundance of potential resources of metallic minerals in many deposits that have been explored in the past. This suggests that, although there is potential in the UK, significant barriers remain in all three of the UNFC axes, which need to be carefully considered if new mines are to be brought into production as part of strategies to reduce reliance on imports to improve security of supply.

This is particularly pertinent when considering the metals required for new technologies and the energy transition, for example lithium. Due to high demand for these technologies, these commodities are subject to much scrutiny (Brown et al., 2016; House of Commons Science and Technology Committee, 2011; UK Government, 2018) with regards to how production and supply within the UK can be improved. However, this analysis shows all current data on lithium are classified in the lowest classes of the UNFC ('E3', 'F3' and 'G3 or 'G4'), suggesting that indigenous production, if it were to happen, could be many years away when considering the typical length of exploration programmes and the planning process in the UK. Nevertheless, exploration for lithium in parts of the UK is ongoing (British Lithium, 2020; Cornish Lithium, 2020) and this is likely to move the position of some resources along the $\mathrm{G}$ axis as geological confidence improves. Additionally, research is underway into the technologies required to convert UK-sourced lithium into the lithium carbonate required for batteries (Li4UK, 2021) and this will move some UK resources along the $\mathrm{F}$ axis in UNFC. However, neither of these actions in themselves will lead to the opening of a new mine. For this to happen there also needs to be movement along the UNFC's E axis with regards to the economic, social and environmental aspects. This demonstrates the usefulness of the UNFC system for identifying all the areas that need attention in the development of potential mining projects while maintaining a realistic perspective on such projects.

Datasets such as the one presented in this paper are designed to assist resource management, strategic decision-making and planning. Accordingly, it is important to demonstrate clearly what data do and do not mean. Figures where confidence is low, for instance in class ' $\mathrm{E} 3$ ', ' $\mathrm{F} 3$ ' and ' $G 4$ ', may be very large but are unlikely to be worked in the near or medium term. These resources represent stocks of geological material in the ground that may be available to work at some point in the future depending on economics, technical, environmental and social feasibility and further geological investigation. They do not represent stocks of material that are available for extraction in the short term. However, inclusion of such low confidence estimates is important because they show that in many cases geological availability is not the primary barrier to resource development.

In contrast, data where confidence is high in all axes, for example 'E1', 'F1' and 'G1', represent reserves that are currently available for extraction. However, such data are dynamic entities controlled by economic and technical factors. The classification is not fixed in time and can change for many reasons. An example from this study is the Drakelands tungsten-tin mine in Devon, which was in production between 2015 and 2018. Here, due to difficulties in mineral processing and a lack of financial liquidity of the owner, the $\mathrm{E}$ and $\mathrm{F}$ axis classification 
Table 1

UNFC classes for the UK resource inventory (as of 1/1/2021).

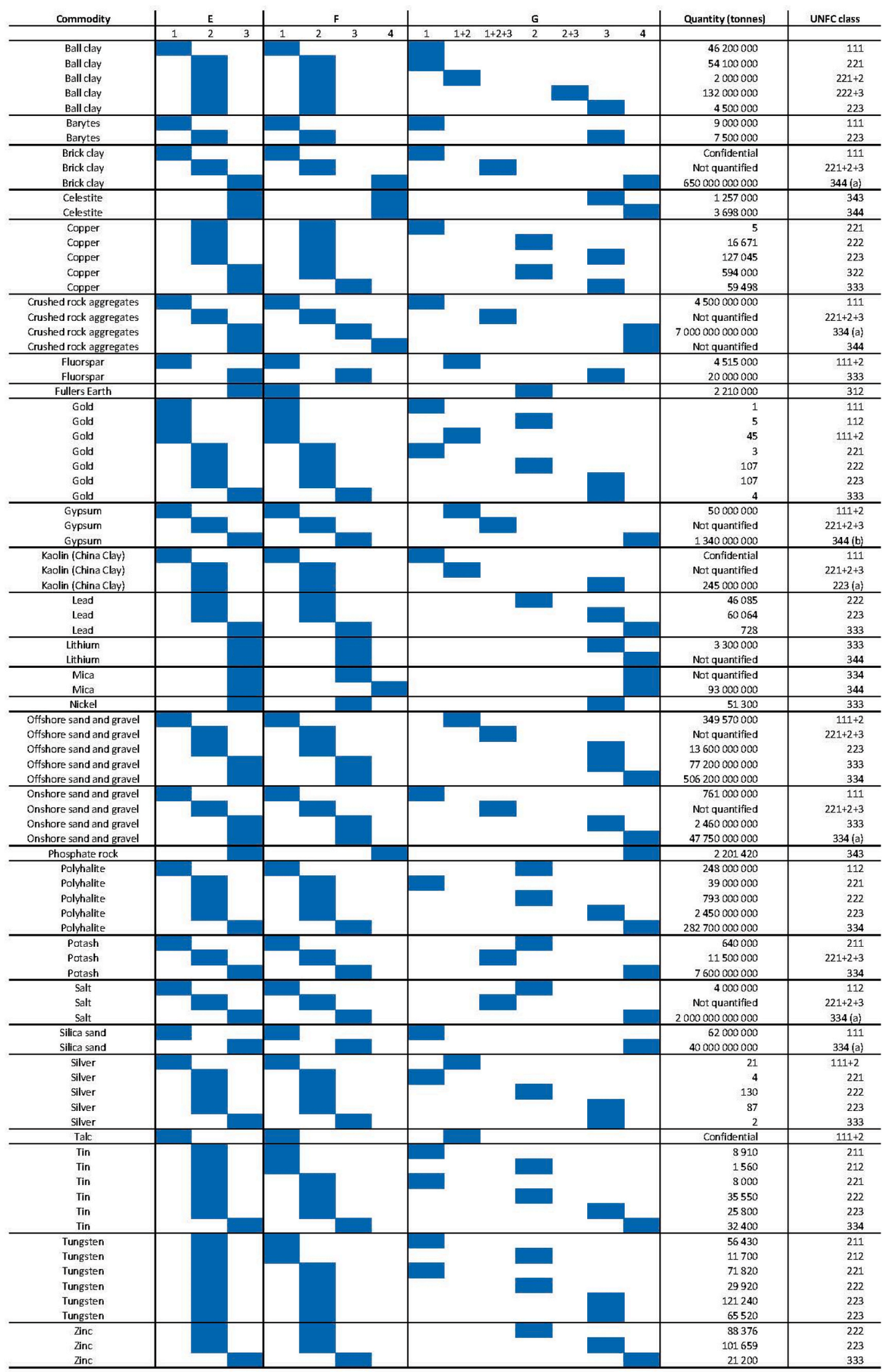


changed to lower classes overnight when the owner's bankruptcy was declared in 2018 (Mining Journal, 2018). However, the stocks of material in the ground have not changed and the classification will alter if the mine is brought back into production. A change in classification may also occur where an increase in a commodity price improves the economic viability of a project, therefore, raising its position on the $\mathrm{E}$ axis. Consequently, the data represent a snapshot in time. It is, therefore, important to review mineral resource data regularly to ensure it reflects current circumstances.

Such changes and flexibility highlight the UNFCs strength as a resource management tool. By showing resources in the context of the each UNFC axis, the barriers to development can be clearly demonstrated. This can be used to both assist and progress the development of resources, as well as providing the ability to compare different projects to assess the best options for development in an environmental and socio-economic context.

It important to remember that a national inventory is intended for strategic, national-level policy making and not to inform investors who are considering an investment via a stock exchange or otherwise directly into a project. The latter group of stakeholders should refer to more detailed assessments on a project specific basis carried out by certified 'competent persons' as defined by international systems of reporting such as those aligned to the CRIRSCO template.

\subsection{Issues in using UNFC for national inventories}

This study has shown that UNFC is useful for bringing together large amounts of data from disparate sources and aggregating resource information from many projects. However, this is a complex task in which it is not easy to maintain consistency and accuracy.

Regardless of the data type used, even for well understood modern industry standard figures, many of the steps involved in classifying resources according to the UNFC involve qualitative and subjective judgments based on expert opinion. For instance, what constitutes "a low level of confidence" (a criterion in many UNFC classes)? This may be difficult to assess if limited information is available to illustrate the amount of exploration work or analysis that has been undertaken on a deposit or occurrence. For the diverse and varied data types that are typically available for national resource inventories, an approach that is overly prescriptive will be unable to cope. This was particularly the case when this study classified resources based on data from historic reports, where critical metadata on factors such as number of boreholes drilled were absent. Indeed, the UNFC classes do not include rules that can be simply followed in an automated way. This is considered to be one of the classifications strengths, because it provides sufficient flexibility to include all relevant data types. However, it is therefore essential that those using UNFC understand these intricacies to ensure consistency of results and that there is good communication between UNFC practitioners to ensure this.

One of the main purposes of such a classification exercise is to produce aggregated data for sector wide comparisons. One very important point regarding aggregation of data is how to deal with metal contents and grade information. Information regarding metallic mineral deposits in standard industry reports is usually expressed in terms of tonnage of ore and the grade of metal contained within it. This is a useful description of a deposit as it simply conveys the difference between large low-grade deposits and small high-grade deposits, which are often treated very differently in terms of mineral extraction. However, it is difficult to maintain this resolution in aggregated UNFC data. In this study, the most appropriate method in such cases was to calculate the metal content of the deposit by multiplying the reported tonnage by the grade. This allows data aggregation but resolution concerning the grade and size of the available resources is lost.

Due to the breadth of factors that need to be incorporated into the UNFC process, care needs to be taken to ensure the relevant expertise is available (there is a requirement in UNFC for involvement by a 'competent person' or 'competent authority' in classification). Typically, work on national resource inventories are carried out by national geological surveys, which hold the required geological datasets and have sufficient understanding of the national minerals industry. These organisations typically have expertise in classifying according to the G axis but perhaps less experience related to the $\mathrm{E}$ and $\mathrm{F}$ axes which requires knowledge of many non-geological factors. For example, understanding of mineral-processing technologies (i.e. the division between ' $\mathrm{F} 1$ ', ' $\mathrm{F} 2$ ' and ' $\mathrm{F} 3$ ') is required to accurately determine whether a project is technically feasible. This may be difficult for a geologist to assess. This study has assumed that if production has occurred in the past at a specific location, then it is technically feasible going forward. Although this may not actually be the case, such assumptions may be necessary for the purpose of compiling a national minerals inventory.

However, by setting out a clear decision flow process, as this study has presented, the required knowledge gaps can be identified and suitable experts consulted in order to complete the classification to an adequate standard for the purpose of a national inventory.

\subsection{Data gaps}

Although UNFC is a powerful tool for classifying resource data, a crucial point for such inventories is that there are many resources for which data are simply not available. This could be for a number of reasons:

a) Data may be confidential e.g. kaolin, which is a significant commodity in the UK in terms of value, but the industry is controlled by only two companies operating at a few sites, making the disclosure of detailed information likely to reveal commercially sensitive data. In cases such as these the presence of an operating project indicates the existence of a 'E1 F1 G1' category. Even if its value is unknown. Despite the absence of data it is important to recognise the existence of these resources;

b) Data may not be collected e.g. sand and gravel, for which there is an active industry in the UK, but no data are collected for certain resource classes; or

c) Data may simply not exist e.g. cobalt, which although present in the UK, is little known due to its by-product status and historical lack of exploration and economic interest (British Geological Survey, 2020).

How these gaps are dealt with needs consideration in order to provide an accurate estimate of geological stocks. This study has included some UNFC classifications for certain commodities as 'unquantified' or 'not estimated', where specific data gaps are known (e.g. crushed rock, brick clay and salt). However, for certain commodities there also may be unknown data gaps and this needs to be recognised, i.e. for co- and byproduct minerals (discussed later) or for minerals for which little exploration or research have been undertaken to date i.e. cobalt or lithium in the UK.

For many commodities, there are only a few deposits that have been discovered and studied sufficiently for data to be available. However, it is possible that other deposits also occur but are concealed or at depth. It is possible to estimate such quantities using probabilistic modelling (Cunningham et al., 2008) or if new exploration activities are undertaken. However, these methods are complex, resource intensive and outside the scope of this study. Therefore, it needs to be recognised that undiscovered resources will generally not be included in compilations of available data such as this. It is entirely possible for deposits to exist but be undiscovered. Only deposits for which data is available have been included here.

For other, geologically less-complex minerals, e.g. aggregate and industrial minerals, this study was able to draw on holistic national level studies that have estimated total 'geological availability' of minerals using spatial data (Bide et al., 2020) to fill some of these data gaps. When estimates are carried out in this way, it frequently results in very large 
tonnages as the wide range of constraints (socio-economic, etc.) are not considered. However, these will always be classified to the lowest classes of UNFC and the majority of these quantities should be considered as unavailable for extraction in the short or medium term.

Another common data gap occurs where multiple commodities are present in a single deposit, such as a polymetallic ore deposit. In such cases, it is common that data will only be available for the main commodities of interest, i.e. those available to extract under certain economic conditions. Any additional commodities may be below current economically workable cut-off grades or not considered necessary for the overall economic viability of the deposit and therefore not reported. Similarly, data are rarely available for by-product minerals, which may be recovered alongside the main commodity of interest, for example lead produced by fluorspar operations in the Southern Pennine Orefield in England. In these examples if data are available they may be contained in historic reports as opposed to more modern industry data. Consequently, it is common for the secondary commodities to be known with lower confidence than the primary product in multi-commodity deposits.

\section{Conclusions}

Reporting systems for minerals resources that are commonly used by the extractive industry are focused on delivering data to ensure investor confidence. Whilst this has shown to work well within with regard the data requirements of stock exchanges and financial regulators, as well as allowing economic management for mining projects over their lifecycle, it is insufficient for national level long term understanding of national and regional resources inventories. This requires the inclusion of additional data and a different approach. UNFC provides a framework for such a classification system for harmonised national scale consideration of resources issues and this study demonstrates, by using practical examples, that UNFC is a versatile tool which can be applied to a wide range of data types. However, its application is not simple and, in many cases, it is very difficult to apply 'hard and fast' rules to enable existing data to be converted to UNFC principle due to the heterogeneity of the data and the broad range of geological, social and environmental situations encountered. Therefore, care needs to be taken to ensure the application of UNFC categorisation is done consistently. The decisionflow tools presented in this case study aid with this.

Presenting mineral resource data in accordance with the UNFC allows comparison of data for different commodities in the resource inventory, and also comparison with similar resource datasets held by other countries. This enables inter-regional or international comparison and aggregation, and also supports the creation and adoption of evidence-based raw material strategies. By portraying the data in this way, it is also easier to begin to integrate them into resources management systems (for example the United Nations Resource Management System, UNRMS). This helps to identify barriers to resource development and the interventions required to mitigate them, while balancing the requirement of resource and environmental management.

Despite its strengths, the UNFC is not a global panacea for presenting harmonised mineral resource data. There remain significant issues with data gaps, consistency of approach, and lack of bridging documents between some classifications and UNFC. One of the most significant issues is the data gaps caused in UNFC by using industry data that is not designed to capture a full picture of resource stocks. This demonstrates the need to engage with relevant experts when compiling such resource inventories to ensure such data gaps are both understood, and if possible, additional data is incorporated. It is also important to consider that whilst understanding of data gaps is very useful, the knowledge of 'all there is' is not always critical to understanding specific or short-term supply issues, i.e. when considering resource inventories it is important to consider what policy/strategy/research questions are being asked and the timescales involved and the appropriate data selected. The perceived complexity of UNFC may serve to deter its widespread adoption, this study shows however, that UNFC is comparatively simple to use and the most significant issue regarding data harmonisation is the complexity of the data that is required for national inventories. Case studies, and the decision tools, such as presented here, will help to make the use of UNFC on a national level more accessible and encourage its adoption more widely.

\section{Author statement}

Tom Bide: Conceptualization Writing- Original draft preparation, Methodology.

Gus Gunn: Writing - Review \& Editing.

Teresa Brown: Conceptualization, Methodology, Writing - Review \& Editing.

Eimear Deady: Writing - Review \& Editing, Methodology.

\section{Data availability}

Data will be made available on request.

\section{Acknowledgements}

This research was part funded by the European Union's Horizon 2020 research and innovation programme under grant agreement No 776517. Richard Shaw and Carolin Kresse are thanked for their valuable contribution to the study. Paul Lusty is thanked for comments on this paper. The authors publish with the permission of the Executive Director, British Geological Survey (UKRI).

\section{References}

Bide, T., Brown, T., Gun, A.G., Shaw, T., Kresse, C., Deady, E., Delgado, P., Horváth, Z., Bavec, S., Rokavec, D., Eloranta, T., Aasly, K., 2019a. Deliverable 1.5 Good Practice Guidelines for Harmonisation of Resource and Reserve Data.

Bide, T., Brown, T., Deady, E., Gun, A.G., Kresse, C., Shaw, R., 2019b. Technical Guidance Note: the Challenges of Assessing European Critical Metal Resources: Insights from Data Availability and Quality in the UK.

Bide, T., Brown, T., Gun, A., Mankelow, J., 2020. Utilisation of multiple current and legacy datasets to create a national minerals inventory: a UK case study. Resour. Pol. 66, 101654.

Blengini, G., Latunussa, C., Eynard, U., de Matos, C.T., Wittmer, D., Georgitzikis, K., Pavel, C., Carrara, S., Mancini, L., Unguru, M., 2020. Study on the EU's List of Critical Raw Materials (2020): Final Report.

British Geological Survey, 2020. The Potential for Cobalt in the UK. British Geological Survey (Nottingham). https://www2.bgs.ac.uk/mineralsuk/statistics/rawMateri alsForALowCarbonFuture.html.

British Lithium, 2020. Drilling the first lithium holes in UK history! [cited 29/1/2021]. https://britishlithium.co.uk/uk-lithium-exploration/Drilling.

Brown, T., Gunn, A.G., Bide, T., 2019. D1.5.3 Technical Guidance Note: Decision Flow Tools for Classifying Resource Data According to the United Nations Framework Classification (UNFC).

Brown, T., Petavratzi, E., 2015. Report on the availability of mineral statistics. Minerals 4EU WP4 deliverable 4.3. https://vyvi-some2.vy-verkko.fi/gtk/Minerals4EU/Deliv erables.

Brown, T.J., Walters, A., Idoine, N., Gunn, A.G., Shaw, R.A., 2016. Lithium commodity profile British geological survey (keyworth, Nottingham). https://www.bgs.ac.uk/ downloads/start.cfm?id=3100.

Carpenter, C., 2020. Pilot program in Mexico classifies oil and gas projects using UN framework. J. Petrol. Technol. 72. https://pubs.spe.org/en/jpt/jpt-article-detail/?ar $\mathrm{t}=7410$.

Cassard, D., Bertrand, G., Billa, M., Serrano, J.-J., Tourlière, B., Angel, J.-M., Gaál, G., 2015. ProMine Mineral Databases: New Tools to Assess Primary and Secondary Mineral Resources in Europe. 9-58 in 3D, 4D and Predictive Modelling of Major Mineral Belts in Europe. Springer.

Cornish Lithium, 2020. 2020 drilling programme for lithium in geothermal waters [cited 29/01/2021]. https://www.cornishlithium.com/drilling-information/.

CRIRSCO, 2016. Committee for mineral reserves international reporting standards [cited June 2016]. http://www.crirsco.com/welcome.asp.

Crowson, P.C.F., 2011. Mineral reserves and future minerals availability. Miner. Econ. $24,1-6$.

Department For Environment, F a R A, 2012. Resource Security Action Plan: Making the Most of Valuable Materials. Department For Environment, Food and Rural Affairs, London, HMSO.

European Commission, 2008. The Raw Materials Initiative-Meeting Our Critical Needs for Growth and Jobs in Europe. COM/2008/0699 Final. Brussels, European Comission. 
European Commission, 2020. Critical Raw Materials Resilience: Charting a Path towards Greater Security and Sustainability. COM, p. 474, 2020. https://eur-lex.europa.eu/ legal-content/EN/TXT/PDF/?uri=CELEX:52020DC0474\&from=EN. final. (Brussels).

Falcone, G., Conti, P., 2019. Regional and Country-Level Assessments of Geothermal Energy Potential Based on UNFC Principles. European Geothermal Congress, 2019.

FGU, GKZ, CRIRSCO, 2010. Guidelines on Alignment of Russian Minerals Reporting Standards and the CRIRSCO Template. (Moscow).

Grohol, M., 2020. European Union New Green Deal and Raw Material Vision. UNECE. https://unece.org/fileadmin/DAM/energy/se/pdfs/UNFC/UNRMS_Webinar_Susta inable_management_September_2020/1._Grohol_UNECE_Webinar_2_.pdf.

Henley, S., Allington, R., 2013. PERC, CRIRSCO, and UNFC: Minerals Reporting Standards and Classifications, vol. 36. European Geologist.

Horváth, Z., 2018. Data Harmonization in the Service of Sustainable Mineral Resource Management. The Present and Future of the Mining and Geology. Demanovks Dolina, Slovakia, pp. 33-47.

House of Commons Science and Technology Committee, 2011. Strategically Important Metals. The Stationery Office, London. https://www.publications.parliament.uk/ $\mathrm{pa} / \mathrm{cm} 201012 / \mathrm{cmselect} / \mathrm{cmsctech} / 726 / 726 . p d f$.

Indian Bureau of Mines, 2003. Guidelines under MCDR for United Nations FrameworkCclassification of mineral reserves/resources. https://ibm.gov.in/index. php?c=pages\& $m=$ index\&id $=135$.

Jowitt, S.M., Mudd, G.M., Thompson, J.F.H., 2020. Future availability of non-renewable metal resources and the influence of environmental, social, and governance conflicts on metal production. Commun. Earth Environ. 1, 13. https://doi.org/10.1038/ s43247-020-0011-0.

Kaj, L., Ingvald, E., Pettersson, B., Brinnen, K., Makkonen, H., Hokka, J., Aasly, K.A., Heldal, T., Simoni, M., Blystad, P., Heiberg, S., 2018. A Guidance for the Applicaion of the UNFC-2009 for Mineral Resources in Finland, Norway and Sweden.

Li4UK, 2021. Faraday Battery Challenge funded project "li4UK" announces the first domestic production of lithium carbonate from UK sources [cited 29/1/2021]. htt p://www.li4uk.co.uk/news/faraday-battery-challenge-funded-project-li4uk-annou nces-the-first-domestic-production-of-lithium-carbonate-from-uk-sources/.

Lusty, P.A.J., Gunn, A.G., 2015. Challenges to global mineral resource security and options for future supply. 265-276. In: McDonald, I. (Ed.), Ore Deposits in an Evolving Earth. Geological Society, London. Special Publications 393.

McKelvey, V., Kleepe, T., 1976. Principles of the mineral resource classification system of the US Bureau of mines and US geological survey. Geol. Surv. Bull.

Meinert, L.D., Robinson, G.R., Nassar, N.T., 2016. Mineral resources: reserves, peak production and the future. Resources 5, 14. https://www.mdpi.com/2079-9276/5/ $1 / 14$.

Minerals4EU project, 2015. WP4 Deliverable 4.5 Final European Minerals Yearbook.
Mining Journal, 2018. Wolf minerals collapses. Min. J. 18/10/2018. [cited 10/12/2020] https://www.mining-journal.com/capital-markets/news/1348447/wolf-mineralscollapses.

Ministry of the Environment of the Czech Republic, 2016. Mineral commodity summaries of the Czech Republic 2016. http://www.geology.cz/extranet-eng/publications/onli ne/mineral-commodity-summaries/mineral-commodity-summaries_2016_m.pdf.

Parker, D., Petavratzi, E., Mankelow, J., Waugh, R., Bertrand, G., 2015. Minventory: EU raw materials statistics on resources and reserves. Minventory Final Report. htt p://ec.europa.eu/DocsRoom/documents/9625/attachments/1/translations/en/ren ditions/native.

Pedersen, M., Kumeij, S., Burger, A., Cassard, D., Aasly, K.A., Jorgensen, L.F., Tulstrup, J., 2019. Mintel4EU Deliverable D1.2. Project Managment Plan.

Petavratzi, E., Brown, T., 2017. Deliverable D3.2. Final inventory of data on raw materials. Mineral Intelligence Capacity Analysis (MICA). http://www.mica-project. eu/?page_id=99.

Polish Geological Institute, 2017. Mineral resources of Poland. (Warsaw). http ://geoportal.pgi.gov.pl/css/surowce/images/2017/pdf/mineral_resources_of_pola nd_2017.pdf.

Russian Federal Government Agency State Commission on Mineral Reserve, 2008. Classification of Reserves and Probable Resources of Solid Minerals. (Moscow).

Stephenson, P., Weatherstone, N., 2006. Developments in International Mineral Resource and Reserve Reporting. CRIRSCO.

UK Government, 2018. Faraday battery challenge [cited 9/12/2020]. https://www.gov. uk/government/collections/faraday-battery-challenge-industrial-strategy-challenge -fund.

UNECE, 2015. Bridging Document between the Comittee for Mineral Reserves International Reporting Standards (CRIRSCO) Template and the United Nations Framework Classification for Resources (UNFC). (Geneva).

UNECE, 2018a. Bridging document between the national standard of the people's Republic of China classification for resources/reserves of solid fuels and mineral commodities (GB/T 17766- 1999) and UNFC. (Geneva). https://www.unece.org/fi leadmin/DAM/energy/se/pdfs/Comm27/ece.energy.2018.5_e_UNFC_China_Miner als BD FINAL as submitted.pdf.

UNECE, 2018b. Ukraine aligns its national mineral resources classification system to an improved UNFC. https://unece.org/sustainable-energy/press/ukraine-aligns-its-nati onal-mineral-resources-classification-system.

UNECE, 2019. United Nations Framework Classification for Resources Update 2019. (New York and Geneva).

Wagner, M., Bide, T., Cassard, D., Huisman, J., Leroy, P., Bavec, S., Ljunggren Söderman, M., Løvik, A.N., Wäger, P.E.J., Sperlich, K., Baldé, C.P., Schjøth, F., Tivander, J., Brown, T., Petavratzi, E., Whitehead, D., Tertre, F., Mählitz, P.M., Nikolova, V., Horváth, Z., 2019. Optimising Quality of Information in RAw MAterials Data Collection across Europe (ORAMA), Technical Final Report \& Recommendations. (Brussels, Belgium). 